\title{
As desigualdades multiplicadas*
}

\author{
François Dubet \\ Université Segalen, Bourdeaux, France. CADIS, EHESS, Paris, France \\ Tradução : Maria do Carmo Duffles Teixeira \\ Revisão Técnica: Léa Pinheiro Paixão e Maria José Jacques G. de Almeida
}

Podemos assumir duas posições com relação às desigualdades: tentarmos descrever as desigualdades, suas escalas e registros, seu crescimento e sua redução, o que supõe, para não ficarmos em generalidades, escolhermos uma dimensão particular, como o consumo, a educação, o trabalho; ${ }^{1}$ ou também analisarmos as desigualdades como conjunto de processos sociais, de mecanismos e experiências coletivas e individuais. No primeiro caso, corremos o risco de sermos precisos e sem perspectivas e, no segundo, de sermos vagos, mesmo tentando esclarecer certos aspectos da natureza das sociedades em que vivemos.

Escolhi a segunda perspectiva, tentando mostrar a dupla natureza das desigualdades, dentre as quais

* “Les inégalités multipliées", texto da conferência proferida no XVI Congrès International de l'Association Internationale des Sociologues de Langue Française (AISLF), na Université Laval, Québec, Canadá, em julho de 2000. Publicado posteriormente por Éditions de L'Aube, França, em 2000.

${ }^{1}$ Para um balanço desse tipo, cf. A. Birh, R. Pfefferkorn, Déchiffrer les inégalités, Paris, Syros, 1995. algumas se reduzem enquanto outras, ao contrário, se ampliam. Esse movimento não é simples consequiência da globalização e se encontra no centro de nossa vida social e de suas tensões. É preciso também situá-lo na experiência dos atores ou de alguns deles, para que daí possamos tirar algumas conclusões no âmbito da análise sociológica. Se quisermos escapar do simples recenseamento, ainda que crítico, é preciso transformar as desigualdades num objeto sociológico, talvez mesmo num objeto de filosofia política, já que, nesse campo, a relação com os valores e com a política está sempre vivamente presente nas teorias.

\section{A dupla face da modernidade}

Se consideramos a tradição sociológica como a construção de uma representação e de uma descrição da modernidade, é possível distinguirmos dois grandes eixos, duas afirmativas gerais que transcendem diferentes autores e que não são contraditórias na medida em que evidenciam uma das tensões essenciais da modernidade. 
1.1 A primeira das descrições, representada por Tocqueville, identifica a modernidade e o próprio sentido da história com o triunfo obstinado da igualda$d e$. Essa igualdade não constitui a descrição empírica da pura igualdade real das condições de vida, mas sim a extensão de um princípio: o da igualdade dos indivíduos a despeito e para além das desigualdades sociais reais. Isso equivale a dizer que, na modernidade, os indivíduos são considerados cada vez mais iguais e que suas desigualdades não podem encontrar justificativa no berço e na tradição. As castas e as ordens se enfraquecem e as classes se impõem como um critério de desigualdade produzido pela própria ação dos indivíduos no mercado. De outro modo, essa descrição remete à que propõe Louis Dumont quando distingue as sociedades holísticas das sociedades individualistas, as primeiras privilegiando as desigualdades coletivas, tidas como "naturais", e as outras concebendo as desigualdades como o produto da competição entre indiví-

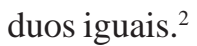

$\mathrm{Na}$ prática, essa interpretação da modernidade significa que as desigualdades justas, naturais, resultam do achievment, da aquisição de estatutos e não mais da herança e das estruturas sociais não igualitárias em seu princípio. Significa, também, que há uma tendência de os indivíduos se considerarem fundamentalmente iguais, podendo legitimamente reivindicar a igualdade de oportunidades e de direitos, reivindicações estas capazes de reduzir as desigualdades reais. Desse ponto de vista, a igualdade é um valor e as desigualdades injustas, ainda por definir, aparecem como um escândalo. É claro que o cenário descrito por Tocqueville foi amplamente confirmado: as sociedades modernas são igualitárias, na medida em que estendem o direito à igualdade, sobretudo o direito à igualdade de oportunidades, aceitando, em termos normativos e políticos, as desigualdades, desde que não impeçam os indivíduos de concorrerem nas provas da igualdade de oportunidades. Uma descrição otimista da modernidade poderia mostrar, sem dificuldade, que

${ }^{2}$ L. Dumont, Essais sur l’individualisme, Paris, Ed. du Seuil, 1983. as sociedades democráticas, no sentido de Tocqueville, conseguiram, pouco a pouco, fazer recuar as desigualdades de castas e ordens, a escravidão, a ausência de direitos políticos, a marginalização das mulheres, as aristocracias de berço. O self made man só pode verdadeiramente vencer nas sociedades igualitárias.

1.2 A segunda face da modernidade é representada por Marx. Para ele, as desigualdades de classes são um elemento fundamental, estrutural, das sociedades modernas - quer dizer, das sociedades capitalistas. À medida que o capitalismo repousa sobre um mecanismo de extração contínua da mais-valia a partir do trabalho e, sobretudo, em que implica o investimento de uma parte crescente das riquezas produzidas, a oposição entre os trabalhadores e os donos do investimento, entre o trabalho e o capital, faz das desigualdades sociais um elemento funcional do sistema das sociedades modernas.

Essa análise é bem mais que uma simples denúncia, de resto banal, das desigualdades, porque acarreta uma abordagem da vida social a partir das desigualdades e das oposições entre as classes sociais. ${ }^{3}$ Bem além da simples filiação marxista, as classes e as relações de classes se tornaram o objeto central da sociologia. As classes e as desigualdades de classes são não só aquilo que precisa ser explicado, mas são, sobretudo, o que explica a maior parte das condutas sociais e culturais. Durante aproximadamente um século, a explicação das condutas pela posição social dos atores se impôs como a prática profissional mais elementar dos sociólogos. As classes e as desigualdades de classes se tornaram, assim, uma espécie de objeto sociológico total. As classes definem grupos de interesses objetivos e suscetíveis de superar o egoísmo dos interesses individuais através de uma consciência de classe. Essa superação tornou-se possível pelos modos de vida que

${ }^{3} \mathrm{O}$ duplo desprezo de Marx pela aristocracia ociosa e o lumpemproletariado são suficientes para mostrar que as desigualdades, como tais, não estão no âmago de uma teoria centrada na exploração e na dominação. 
têm em comum; as classes são também seres culturais e comunidades. Finalmente, as relações entre as classes são também consideradas como relações de dominação e as classes sociais vistas como movimentos sociais, como atores coletivos, graças a uma consciência dos conflitos sociais. Assim, as relações de classes explicam, ao mesmo tempo, os modos de consumo, as identidades coletivas e individuais (os habitus) e a própria vida política parece estruturada por conflitos de classes e pelas orientações culturais que eles determinam. Esse tipo de representação constituiu uma matriz geral bastante compartilhada pelos sociólogos da sociedade industrial até a metade dos anos de 1960 e por sociólogos tão diferentes, como Aron, Darhendorf, Lipset ou Touraine.

Nessa perspectiva, - que convém sublinhar, vai bem além das fileiras marxistas -, as desigualdades sociais constituem mais que um objeto particular da sociologia; elas são, de maneira mais ou menos direta, o objeto da sociologia, irrigando a sociologia do trabalho, a sociologia da ação coletiva, a sociologia dos modos de vida, a sociologia da educação e, de maneira geral, todas as sociologias que optam em graus variados por uma visão crítica. Mas estiveram também presentes num vasto espaço da sociologia funcionalista em que as análises da estratificação e da ordem social se superpõem.

1.3 Essa dupla representação das desigualdades apareceu freqüentemente como não contraditória através dos temas da divisão do trabalho e da integração conflituosa. Se consideramos o funcionalismo como uma filosofia social, como nos sugere o próprio Durkheim em Divisão do trabalho social, as desigualdades de classe e a igualdade dos indivíduos aparecem como compatíveis. Existem desigualdades funcionais e o "socialismo", quer dizer, as organizações sindicais e corporativas, transforma essa divisão em solidariedade. Lembremos que Parsons tentou construir uma teoria das desigualdades definidas a partir de critérios funcionais. ${ }^{4}$ Uma das idéias centrais da socio-

${ }^{4}$ T. Parsons, Nouvelle ébauche d'une théorie de la stratification, Eléments pour une sociologie de l'action, Paris, Plon, 1955. logia das sociedades industriais é a da participação conflituosa e, mais precisamente, das virtudes integrativas do conflito. Como são negociados, os conflitos sociais provenientes das desigualdades engendram um modo de regulação política que os torna compatíveis com o princípio da igualdade dos indivíduos e com as desigualdades funcionais do capitalismo.

Em outras palavras, o encontro da igualdade democrática com as desigualdades capitalistas engendra a formação do Estado-providência e de um sistema de proteções e de direitos sociais. Como as principais desigualdades são oriundas do trabalho, a sociedade salarial organiza a coesão e a integração sociais a partir do trabalho que, ao mesmo tempo, opõe e une os indivíduos. Tal é o sentido da análise de Castel que se coloca implicitamente numa perspectiva "durkheimiana" ao mostrar como o assalariado desenvolve um conjunto de direitos que vão muito além do simples espaço do trabalho. ${ }^{5}$ Marshall adere a uma visão próxima da democracia industrial ao propor um vasto afresco histórico no qual os direitos do indivíduo fecundam os direitos políticos que desembocam nos direitos sociais. ${ }^{6}$

Em suma, na maior parte das análises da sociedade industrial, a dupla face da igualdade é perfeitamente reconhecida, embora pareça, de certa maneira, superável. Mais ainda, ela está na origem da dinâmica social da modernidade, definida simultaneamente por uma aspiração fundamental à igualdade dos indivíduos e por uma desigualdade estrutural ligada a sua historicidade e aos mecanismos de desenvolvimento do capitalismo. É claro que muitas utopias, muitas críticas e alguns movimentos sociais sonharam com o rompimento dessa tensão em nome de uma igualdade pura e perfeita. É assim que Durkheim definia o comunismo como uma utopia por oposição ao socialismo, concebido como um movimento. ${ }^{7}$ Mas, no essen-

${ }^{5} \mathrm{R}$. Castel, Les métamorphoses de la question sociale, $\mathrm{Pa}-$ ris, Fayard, 1995.

${ }^{6}$ T. H. Marshall, Citizenship and social development, Chicago, Chicago University Press, 1977.

${ }^{7}$ E. Durkheim, Le socialisme, Paris, PUF, 1971 (1928). 
cial, a sociologia clássica se construiu mais nessa dialética que contra ela. ${ }^{8}$

\section{Inversão de tendência?}

Na França, pelo menos, consideramos geralmente que os anos de 1945 a 1975, os "Trinta Anos Gloriosos", marcaram o apogeu do sistema de integração da sociedade industrial com o crescimento dos conflitos de trabalho, das negociações coletivas e do Estado-providência em torno de um modelo qualificado, de maneira retroativa, de fordista. Acho essa reconstrução bastante artificial e francamente falsa, tendo, contudo e sobretudo, uma função dramatúrgica: colocar em evidência a ruptura de um modelo de integração. Grande parte da vulgata sociológica francesa mostra a evolução dos últimos 25 anos como uma longa crise, como uma decadência contínua, como um recrudescimento, em todos os sentidos, das desigualdades sociais, como o triunfo de um capitalismo selvagem. Ora, se algumas desigualdades se aprofundaram, outras se reduziram. Para entendermos o que aconteceu, voltemos à dupla face da igualdade ou das desigualdades.

2.1 Apesar da crise econômica e da mundialização, observamos uma ampliação da igualdade sob a forma de uma homogeneização da sociedade. ${ }^{9}$ Não é preciso ser ingênuo ou exageradamente otimista para registrar a extensão da igualdade tocqueviliana. $\mathrm{O}$ traço mais marcante é a mistura das comunidades e, retomando a expressão de Goblot, a substituição das barreiras por níveis. A classe operária não apenas se reduziu, mas também se fracionou e se fundiu no universo das classes médias inferiores com o "desenclave" do hábitat operário. Com a entrada massiva das mulheres no assalariado da atividade terciária e de serviços,

${ }^{8}$ Politicamente, a maioria dos sociólogos da sociedade industrial se definirão como sociais democratas, progressistas, intelectuais de esquerda.

${ }^{9}$ H. Mendras, La seconde révolution française, 1864-1984, Paris, Gallimard, 1988. a maioria dos "casais operários" é composta por um operário e uma dessas trabalhadoras..$^{10}$ Em 1993, a mobilidade estrutural faz com que aproximadamente um de cada dois filhos de operário e mais de um de cada dois filhos de quadro qualificado não permaneça na classe social de seus pais. ${ }^{11}$ Se os níveis de vida não se igualaram, os modos de vida se alinharam em torno de uma norma definida pelas classes médias e pelo consumo de massa. A ampliação da influência da mídia teve seu papel nessa evolução que se manifesta nos vocabulários culto e corrente, nos quais a noção de classe operária foi substituída por noções muito mais vagas como "camadas populares" ou "camadas desfavorecidas", o plural reforçando a imprecisão. $\mathrm{O}$ crescimento de uma pobreza escandalosa, aprisionada em "bairros de exílio", indica, ao contrário, que o movimento de "homogeneização" se manteve, já que tais pobres não são mais pobres que os pobres de antigamente, mas parecem estar reduzidos a esse estado.

Com relação a um grande número de critérios, o acesso igualitário aos bens de consumo cresceu: automóveis, moradia, equipamentos domésticos, estrutura de despesas das famílias, lazeres. É certo que esse crescimento é bem mais contraditório do que nos faz crer uma leitura superficial dos indicadores sociais, como mostra, de maneira exemplar, o acesso à educação. Com a massificação escolar, o acesso aos estudos secundários e superiores aumentou consideravelmente. $\mathrm{Na}$ França, o percentual de filhos de operários que concluem o ensino médio, que fazem o vestibular ou que obtêm um diploma universitário foi multiplicado por mais de quatro nos últimos 25 anos. Mas, se olhamos mais de perto, tal democratização é bastante segregativa, pois os filhos das classes populares se encontram nos setores e formações menos valorizadas e menos úteis, enquanto os filhos das categorias supe-

${ }^{10}$ P. Bouffartigue, Le brouillage des classes, em P. P. Durand e F. X. Merrien, Sortie de siècle, Paris, Vigot, 1991; J. P. Terrail, Destins ouvriers : la fin d'une classe? Paris, PUF, 1990.

11 A. Desrosières, L. Thevenot, Les catégories socioprofessionnelles, Paris, La Découverte, 1996. 
riores adquirem uma espécie de monopólio das carreiras elitistas e rentáveis. ${ }^{12}$ A igualdade cresceu porque a educação não é mais um bem raro, beneficiando a todos, mas ela se tornou um bem muito mais hierarquizado quando as barreiras foram substituídas pelos níveis. Um raciocínio idêntico poderia ser aplicado a outros setores, quer se trate do consumo de bens ou de cultura, do lazer ou de marcas de roupa. Da mesma maneira, as mulheres passaram a ter acesso a grande número de setores que lhes eram, até então, fechados, sem que com isso a igualdade tenha sido reforçada. Mas, se consideramos que o acesso aos bens e aos setores de atividade, até então raros ou proibidos, é um componente da igualdade, parece que a igualdade das esperanças e dos direitos tenha se reforçado apesar do que chamamos de "crise".

2.2 Em compensação, as transformações da estrutura social fizeram emergir outras configurações da desigualdade além das presentes no modelo "clássico" da sociedade industrial. Mais que as desigualdades propriamente ditas, é a fragmentação do mercado de trabalho que marca os últimos anos. Quando a integração em torno de um estatuto estável e de direitos aferentes parecia se tornar regra comum, vimos multiplicar os mercados de trabalho. Podemos não somente opor um mercado primário que oferece empregos estáveis, bem pagos, abrindo carreiras e direitos, a um mercado secundário, composto de empregos precários e instáveis, ${ }^{13}$ mas ainda observar que cada um desses mercados parece se dividir ao infinito pelo jogo da terceirização, da interinidade, dos estágios, dos dispositivos de apoio social, do trabalho a domicílio. Em um mesmo conjunto produtivo e em um mesmo tipo de atividade, encontraremos estatutos extremamente diferentes segundo os graus de flexibilidade da mão-deobra, os níveis de formação e as posições das empre-

${ }^{12}$ P. Merle, Le concept de démocratisation de l'institution scolaire, Population, v. 55, $\mathrm{n}^{\circ} 1,2000$.

${ }^{13}$ S. Berger, M. J. Priore, Dualism and discontinuity, em Industrial society, Cambridge, Cambridge University Press, 1980. sas. A segmentação do mercado de trabalho não se opera apenas em função de necessidades econômicas, ela ativa e exacerba diferenciações sociais em função do sexo, da idade, do capital escolar, da origem étnica. ${ }^{14}$ Com qualificação igual, os salários dos homens e das mulheres atingem uma variação de 5 a $15 \%$. Em 1975, os "contratos de duração indeterminada" atingiam $80 \%$ dos trabalhadores, atingindo hoje apenas $65 \%$. Entre o fim da vida profissional ativa e a aposentadoria criou-se um período com estatutos os mais variados, o mesmo acontecendo, aliás, para os jovens, antes de entrar num emprego estável. ${ }^{15}$ Quanto ao desemprego, ele ainda é a mais flagrante das desigualdades, atingindo grupos sociais bastante "específicos".

Na realidade, já não podemos opor tão claramente, como acreditávamos, os assalariados aos proprietários dos meios de produção, nem mesmo em razão da extensão do assalariado. Na maioria das sociedades ocidentais, criou-se uma fronteira, mais ou menos visível, opondo os integrados aos excluídos. Mesmo que tal fronteira não esteja demarcada e que muitos indivíduos circulem de um mundo para o outro, a estrutura social das nossas sociedades se "latino-americaniza" com o crescimento da pobreza, da incerteza, da economia informal. O declínio da sociedade salarial acarretou um deslocamento da questão social que se assemelha em vários pontos ao da época da entrada na sociedade industrial, na medida em que o núcleo dos problemas desloca-se da fábrica para a cidade, para as periferias ou centros de cidade degradados, onde se concentram os grupos mais frágeis, mais pobres, mais estigmatizados. Há vinte anos, a França vem se habituando às rebeliões urbanas, às violências escolares e ao desemprego endêmico. As formas tradicionais do Estado-providência estão ameaçadas tanto no plano econômico, quanto sob o ponto de vista de sua legitimidade ideológica.

14 A. Perrot, Les nouvelles théories du marché du travail, Paris, La Découverte, 1992; M. Maruani, H. Mendras, op. cit.; E. Reynaud, Sociologie de l'emploi, Paris, La Découverte, 1993.

${ }^{15} \mathrm{~S}$. Paugam, Le salarié de la précarité; les nouvelles formes de l'intégration professionnelle, Paris, PUF, 2000. 
A estrutura de classes das sociedades industriais passa por uma mutação que impõe a distinção entre vários grupos constituídos a partir dos contratos de trabalho, dos rendimentos e das posições dos setores de atividade na competição econômica. ${ }^{16}$ Relações de classes específicas se estabelecem no mundo dos competitivos entre setores econômicos atuantes no plano internacional. Outras se estabelecem no mundo dos protegidos, dos que obtêm seu estatuto por sua influência política, como os funcionários, o pessoal da saúde, os agricultores generosamente subvencionados. A dominação desses dois setores sobre o resto da sociedade engendra um movimento geral de externalização dos custos e de terceirização na direção de um setor social precário, atingindo tanto os empregadores, quanto os empregados. Finalmente, constitui-se um setor excluído, assistido pelas políticas sociais, que se esforça para conquistar certa autonomia dentro da economia informal. Às desigualdades que opõem esses mundos se acrescentam as desigualdades internas a cada um deles e, sob este aspecto, as pessoas vivem num duplo registro de desigualdades. Além disso, esse tipo de representação das desigualdades ultrapassa, em muito, o simples quadro das sociedades nacionais em razão das implantações e deslocamentos das empresas e da constatação de que os excluídos formam freqüentemente enclaves vindos do Sul pobre para o Norte rico, enquanto que os pólos de riqueza e de desenvolvimento do Sul podem aparecer como enclaves do Norte rico num Sul pobre.

Do ponto de vista analítico, o encontro de uma igualdade tocqueviliana contínua com as transformações da estrutura social acarretou o declínio das análises em termos de classes. Os anos de 1970 foram dominados pela tentativa - e pelo fracasso - de uma renovação da teoria de classes marxista. ${ }^{17}$ Hoje, a análise das desigualdades (não sua descrição) é confron-

${ }^{16}$ Cf. P. N. Giraud, L'inégalité du monde, Paris, Gallimard, 1996; R. Reich, L'économie mondialisée, Paris, Dunod, 1993.

${ }^{17} \mathrm{Na}$ França, é o nome de Poulantzas que é o mais associado a esse esforço. tada à separação entre a estratificação e as relações de dominação, à separação daquilo que a noção de classe "total" visava justamente unificar. As escalas de estratificação procuram combinar vários registros e estabelecem fronteiras, muitas vezes incertas, como as que separam os operários dos empregados de serviços. ${ }^{18}$ As desigualdades de rendimentos variam sensivelmente, se levamos em conta salários, rendas e rendimentos indiretos. Dessa maneira, na França, enquanto as diferenças de salário diminuíram, $10 \%$ das famílias continuam a deter metade do patrimônio e as desigualdades se tornam ainda mais marcadas, se levamos em conta o critério de idade. ${ }^{19}$ Mais que nunca, não nos é possível construir escalas de estratificação confiáveis a partir da idéia de classes antagônicas. As relações de dominação nem por isso desapareceram, pelo contrário; mas já não permitem que as desigualdades reais sejam descritas objetivamente. A dominação já não se insere nas relações de classes concretas e estáveis. Os problemas da estratificação e da mobilidade se destacam dos conflitos estruturais e a análise das desigualdades não conduz a uma visão organizada e estruturada das relações sociais. ${ }^{20}$ Do mesmo modo que as desigualdades são múltiplas, os registros da dominação não são homogêneos, como deixa claro a teoria dos "capitais" de Bourdieu. ${ }^{21}$

${ }^{18}$ A. Desrosières, L. Thevenot, op. cit.

${ }^{19}$ A. Bayet, L'éventail des salaires et ses déterminants, $L a$ société française, Données sociales, INSEE, 1996; F. GuillaumatTaillet, J. Malpot, V. Paquel, Le patrimoine des ménages: répartition et concentration, La société française, Données sociales, INSEE, 1996.

${ }^{20}$ A. Touraine, La société postindustrielle, Paris, Denoël, 1969.

${ }^{21} \mathrm{O}$ fato de que um destes capitais desempenha papel "determinante" traz de volta uma postura, em última análise, marxista "clássica". Se consideramos que eles são independentes, a questão da ligação entre a dominação e a estratificação coloca-se novamente. Parece que a análise de Bourdieu oscila entre essas duas posições. 


\section{As desigualdades multiplicadas}

Por um lado, as desigualdades "pré-modernas" continuam a se reduzir e a aspiração à igualdade de oportunidades e direitos se fortalece. Por outro lado, as desigualdades "funcionais" não se reduzem e, freqüentemente, se consolidam, sobretudo nas duas extremidades da escala social. $\mathrm{O}$ encontro desses dois processos exacerba a sensibilidade às desigualdades, como indica o desenvolvimento de novos movimentos sociais: as lutas feministas, os movimentos comunitários ou os combates das minorias. Freqüentemente ligada a esses movimentos, às vezes influenciada pela sociologia anglo-saxônica, a sociologia francesa dedicou inúmeros trabalhos ao estudo das novas desigualdades. Tais desigualdades não são evidentemente novas, são mesmo, na maioria das vezes, menos pronunciadas que as de antigamente, como no caso das desigualdades sexuais, mas constituem um novo objeto de pesquisa e de análise.

3.1 A posição dominante das análises, em termos de classe, foi abalada pela introdução de novos critérios de definição das desigualdades. Em trinta anos, a população ativa se feminizou consideravelmente alcançando 44,7\% em 1994. No entanto, todos os estudos mostram que essa ascensão das mulheres indo, incontestavelmente, ao encontro de uma extensão da igualdade, não elimina, de fato, a maioria das desigualdades. Além das diferenças salariais, a diferenciação dos setores de emprego se manteve, diríamos mesmo, se aprofundou. As mulheres dominam os serviços, são majoritárias na educação e na saúde, mas não entram na produção, na política ou em outros setores que continuam predominantemente masculinos. Poderíamos falar de emancipação segregativa ou de emancipação "sob tutela". ${ }^{22}$ Pior ainda, a autonomia das mulheres assalariadas freqüentemente se traduziu

${ }^{22}$ R. M. Lagrave, Une émancipation sous tutelle. Education et travail des femmes au XXe siècle, em G. Duby, M. Perrot (ed.), Histoire des femmes en Occident, Le XXe siècle, Paris, Plon, 1992. por uma sobrecarga de trabalho e por opressões "privadas", já que a divisão do trabalho doméstico não foi sensivelmente afetada por tal emancipação. Essa autonomia também aumentou consideravelmente a vulnerabilidade das mulheres chefes de família, visto que são menos "protegidas pela tradição" e mais afetadas pela pobreza em caso de dificuldades econômicas e de divórcio. De maneira geral, os domínios "privados" e "públicos" continuam bastante distantes e específicos, sexualmente marcados. ${ }^{23}$ Quanto mais se refinam os estudos, mais se evidencia a manutenção ou a consolidação de microdesigualdades. Assim, as meninas são as grandes beneficiárias da massificação escolar; mas, ao mesmo tempo em que obtêm melhores resultados que os rapazes, elas não se orientam para carreiras mais rentáveis, sobretudo as de formação científica. ${ }^{24}$ Os estudos mostram que as mulheres não ganharam em todas as frentes e que essa incontestável igualdade é "paga" por novas desigualdades, tanto mais insuportáveis por entrarem em choque com uma progressão "objetiva" da igualdade.

As desigualdades étnicas sofreram um processo semelhante. Na França, de maneira geral, os imigrantes e, sobretudo, seus filhos se integram progressivamente à sociedade francesa. ${ }^{25}$ Mas tal integração, construída a partir de indicadores bastante globais, não impede que uma forte segregação se instale com a formação de zonas de exílio étnicas nos bairros mais pobres e, sobretudo, com a demonstração patente da segregação e do racismo nas esferas da moradia e do emprego. ${ }^{26}$ Paradoxalmente, nesse domínio, a consciência das desigualdades está mais viva hoje que ontem porque, ao mesmo tempo em que são "integrados", os imigrantes são "destinados" a certos bairros, a certos empregos e esbarram quotidianamente em inú-

${ }^{23} \mathrm{~F}$. Héritier, Masculin, féminin, la pensée de la différence, Paris, Odile Jacob, 1996.

${ }^{24}$ M. Duru-Bellat, L'école des filles, Paris, l'Harmattan, 1990.

${ }^{25} \mathrm{M}$. Tribalat, De l'immigration à l'assimilation, Paris, La Découverte, 1996.

${ }^{26}$ P. Bataille, Le racisme au travail, Paris, La Découverte, 1997. 
meras manifestações de racismo. Esse paradoxo remete a um mecanismo, ainda novo para a França, o da transformação dos imigrantes em minorias. ${ }^{27}$ Enquanto os imigrantes eram acolhidos num processo de integração econômica específica, associado às aspirações ligadas aos sonhos de volta, seus filhos são, de maneira considerável, assimilados à cultura do país que os acolhe, mesmo se sentindo excluídos da participação econômica e social. A geração dos pais era integrada e não assimilada; a dos filhos, assimilada, não se sente integrada, percebendo-se como uma minoria excluída, rejeitada, que pode devolver aos dominantes os estigmas que lhe são atribuídos. Enquanto os imigrantes constituem a faixa inferior da classe proletária, as minorias se sentem definidas apenas por suas identidades e "estigmatizações" étnicas e culturais.

A distribuição das desigualdades entre as faixas de idade transformou-se profundamente durante os últimos 30 anos, em função das políticas de emprego e das formas de redistribuição social. Enquanto os jovens dos "trinta gloriosos", nascidos logo após a guerra, beneficiaram-se de condições bastante favoráveis com relação aos mais velhos, houve uma inversão da tendência e a idade torna-se um fator importante das desigualdades. Os jovens são mais atingidos pelo desemprego que os adultos e, sobretudo, estão condenados a um longo período de incerteza e de precariedade antes de conseguirem um emprego estável. ${ }^{28} \mathrm{~A}$ demografia, a situação econômica e as políticas sociais se conjugam para explicar essas novas desigualdades, pois tudo acontece como se a França tivesse "escolhido" castigar os jovens. É claro que não se trata verdadeiramente de uma escolha, mas, sim, da conseqüência de múltiplas escolhas que acarretaram principalmente uma desvalorização dos diplomas e um crescimento do custo de entrada na vida adulta, definida como o momento em que se podem engajar projetos de vida. Enquanto nos anos de 1960 os jovens eram

${ }^{27}$ F. Dubet, Immigration, qu'en savons-nous? Paris, $\mathrm{La}$ Documentation Française, 1989.

${ }^{28} \mathrm{~L}$. Chauvel, Le destin des générations. Structure sociale et cohortes en France au XXe siècle, Paris, PUF, 1998. empregados com salários relativamente próximos aos dos adultos, hoje, o diferencial se aprofundou de forma considerável. ${ }^{29}$ Tais desigualdades globais, entre as diferentes faixas de idade, não impedem, evidentemente, que se formem ou se mantenham outras desigualdades dentro de cada grupo de idade, em função dos sexos, dos tipos de formação, do emprego. A descrição das desigualdades é inesgotável.

3.2 Poderíamos alongar indefinidamente a lista das "novas" desigualdades, conscientes de que sempre correríamos o risco de contrariar esse ou aquele grupo por não reconhecê-lo como vítima de desigualdades. Mas a análise dessas múltiplas desigualdades transformou sensivelmente o olhar dos sociólogos, porque a maioria delas não se reduz nem ao berço nem à posição de classe, mas resulta da conjugação de um conjunto complexo de fatores, aparecendo mesmo, muitas vezes, como o produto, mais ou menos perverso, de práticas ou políticas sociais que têm como objetivo, justamente, limitá-las. Mesmo que a crítica dos efeitos perversos do Estado-providência nunca seja desprovida de reservas, é forçoso admitir que alguns desses efeitos perversos não podem ser ignorados, especialmente os efeitos de dependência e de estigmatização e, sobretudo, que tais políticas são freqüentemente favoráveis àqueles que são menos desfavorecidos. A análise dos mecanismos de transferências sociais mostra que, freqüentemente, são as classes médias as principais beneficiárias no setor da educação ou da saúde, por exemplo. ${ }^{30}$

A sociologia da educação ilustra bem tal transformação da visada sociológica. Por muito tempo, o paradigma da reprodução dominou a sociologia da educação, atribuindo unicamente às desigualdades sociais a "responsabilidade" pelas desigualdades esco-

${ }^{29}$ C. Baudelot, R. Establet, Avoir trente ans en 1968 et 1998 , Paris, Ed. du Seuil, 2000.

${ }^{30} \mathrm{Cf}$. X. Gaullier, La machine à exclure, em L'Etatprovidence, Arguments pour une réforme, Paris, Le Débat/ Gallimard, 1996; préface de F.X. Merrien à G. Esping-Andersen, Les trois mondes de l'Etat-providence, Paris, PUF, 1999. 
lares. O paradigma do individualismo metodológico propôs uma alternativa teórica que não mudava o raciocínio nesse ponto. Nos dois casos, a escola era considerada como uma caixa preta neutra que simplesmente gravava as desigualdades sociais sob a forma de desvantagens culturais num caso e de agregação de cálculos racionais socialmente situados no outro. Em reação a teorias que podem levar a certo "fatalismo" político e sob a influência da "nova sociologia" da educação inglesa, numerosos estudos se empenharam em mostrar que a escola desempenhava papel próprio na produção das desigualdades. ${ }^{31}$ Verificou-se primeiro que a oferta escolar estava longe de ser homogênea, mesmo num sistema republicano, reconhecido como homogêneo: a oferta é de melhor qualidade quando destinada aos mais favorecidos, e isso apesar dos esforços de discriminação positiva. Em seguida, toda uma microssociologia da educação mostrou que as interações escolares e as expectativas recíprocas por parte dos professores e alunos beneficiavam os alunos oriundos das classes média e superior. Diversos “efeitos" não igualitários foram evidenciados: efeito classe, efeito estabelecimento de ensino, efeito professor. Dessa maneira, a escola acrescenta às desigualdades sociais suas próprias desigualdades. Por muito tempo, pensamos que uma oferta igual pudesse produzir igualdade. Hoje percebemos que não só ela não é realmente igual, mas que sua própria igualdade pode também produzir efeitos não igualitários somados aos efeitos que ela deseja reduzir. Deslizamos assim, sem nos darmos conta, para uma filosofia política menos centrada na igualdade que na eqüidade.

3.3 Coloquemo-nos agora do lado dos atores sociais e dos indivíduos. Se excluímos os grupos situados nos dois extremos da escala social e das relações de dominação, a incongruência estatutária torna-se a regra. ${ }^{32}$ Sabemos que Weber distinguiu classe, status

${ }^{31}$ M. Duru-Bellat, A. Van-Zanten, Sociologie de l'école, Paris, Armand Colin, 1999.

${ }^{32}$ G. E. Lenski, Status cristalizations : a non vertical dimension of social status, American Sociological Review, XIX, 4, 1954. e poder como dimensões analiticamente independentes da posição de um indivíduo. A intuição "weberiana” é hoje uma realidade. ${ }^{33}$ A organização das desigualdades em torno simplesmente das classes sociais aparece como um fenômeno historicamente contingente em razão do predomínio da sociedade industrial, da manutenção das barreiras, das distâncias "aristocráticas" e da organização da vida política em termos de representações, mais ou menos grosseiras, dos interesses de classes. Quando essas diversas dimensões se dissociam, elas o fazem em cada grupo e em cada indivíduo, cujas posições, nas diversas escalas, já não são necessariamente congruentes. Uma pesquisa realizada nos anos de 1980, junto a operários americanos, revela que os mesmos se definem como "trabalhadores" em termos de identidade profissional, como "classe média" em termos de consumo e como "povo" em termos de participação política. ${ }^{34} \mathrm{O}$ ator está mais ou menos em condição de igualdade com os outros, em função das diferentes esferas que constituem sua situação: seu sexo, sua idade, seu emprego, seu trabalho, sua formação e suas origens. À medida que tal diversidade se depara com a afirmação da igual dignidade de todos como postulado central das sociedades democráticas, entendemos perfeitamente porque a identidade aparece menos dada que construída e reivindicada pelos indivíduos. Segundo seus projetos e contextos de ação, os indivíduos "optam" por mobilizar e priorizar tal ou qual dimensão de sua identidade e de sua experiência. Enquanto os operários podiam agir como operários porque não tinham, então, outras identidades disponíveis, hoje, a "opção" é por agir e se expor enquanto mulher, trabalhadores, "bretão", religioso, diplomado. É também por tal razão que os temas dos estigmas e da imagem de si adquiriram tamanha amplitude. A construção e exposição de si e de seu "visual" não se explica apenas pela submissão ao consumo de massa, mas também pela necessidade de

${ }^{33}$ R. Crompton, Class and stratification, Londres, Polity Press, 1993.

${ }^{34}$ E. Hobsbawm, Farewell to the Labor Movement?, Politics for a rational left, Londres, Verso, 1989. 
expor, constantemente, ao olhar dos outros, a identidade escolhida. Com referência aos movimentos sociais, também eles perderam o caráter "total" e a vocação para englobar a totalidade de uma experiência e de um ser; eles se multiplicaram, assumindo tal ou qual dimensão da identidade individual - o trabalho, a sexualidade, o status profissional, as escolhas éticas sem que nenhuma delas chegue a se impor às demais.

Esse trabalho de construção de si, através da multiplicidade dos registros das desigualdades, é por sua vez bastante desigual, pois mobiliza recursos também distribuídos de maneira muito desigual. Aliás, uma das características da expressão moderna das desigualdades é a de ter tirado dos pobres a capacidade de construir plenamente para si uma identidade. Como nomear os moradores dos conjuntos habitacionais de periferia conhecidos como "difíceis"? Habitualmente, e no fundo de maneira inaceitável, eles são caracterizados pelos problemas tal como definidos pelas políticas sociais que deles se incumbem: pobres, desempregados, imigrantes, famílias "desestruturadas", quando não delinqüientes. Essas pessoas são definidas pelas categorias de uma "desvantagenlogia" que corresponde aos programas das políticas públicas. A utilização das classificações objetivas já não resolve, pois esse mundo comporta, ao mesmo tempo, operários e empregados, desempregados, "famílias assistidas", outros que "se viram", e se ninguém é rico, nem todos são pobres, pois alguns fazem percursos de mobilidade ascendente, enquanto outros - a maioria - se sentem resignados com tal situação. Será que eles formam uma comunidade popular? Certamente não, pois esse mundo fracionado numa hierarquia sutil e complexa não compartilha as mesmas normas. Ele põe em prática, de bom grado, identificações negativas, recusando-se a se identificar com seus vizinhos, principalmente com os imigrantes, cujos laços comunitários são estigmatizados e geralmente considerados perigosos. A "homogeneização" e, na França, as políticas públicas romperam os mecanismos de formação das comunidades populares, sem falar da mídia que apenas lhes devolve a imagem de seus problemas. Finalmente, aqueles que poderiam desempenhar um papel na construção dessas identidades, os mais dinâmicos, os mais qualificados e os mais capazes de exercer uma influência, deixam esses bairros logo que podem..$^{35}$

Do ponto de vista subjetivo, os moradores de tais bairros se definem como de classe média, partilhando ou procurando partilhar o modo de vida das classes médias. Essa identificação é ainda mais forte por estar no âmago das definições de normalidade emitidas pela escola e pelos serviços sociais. Mas, ao mesmo tempo, esses atores não estão em condições de satisfazer tais aspirações devido a sua situação de pobreza e acabam interiorizando os estigmas que lhe são impostos, descarregando-os em seus vizinhos. A partir daí, sua experiência limite das desigualdades é vivida como "colonização" interna, "colonização" da experiência vivida, já que se identificam com um ideal igualitário que as invalida. Mesmo que sintam com intensidade a distância que separa seu desejo de igualdade de suas desigualdades reais, tais desigualdades estão muito fragmentadas para poderem reunificar sua experiência e para engendrarem uma mobilização contra uma condição tida como intolerável. Na realidade, salvo a violência dos jovens, os mais desprovidos estão praticamente privados de capacidades coletivas de protesto.

\section{A experiência social das desigualdades}

Nunca a contradição entre as duas faces da igualdade (ou das desigualdades) foi tão aguda. Nunca $o$ confronto entre a afirmação da igualdade dos indivíduos e as múltiplas desigualdades que fracionam as situações e as relações sociais foi tão violento e tão ameaçador para o sujeito.

4.1 A obrigação de ser livre, de ser sujeito, de ser o autor de sua vida, que caracteriza o próprio projeto da modernidade, é indissociável da afirmação da

${ }^{35}$ C. Avenel et al., Le DSQ des Hauts de Garonne, analyse sociologique, Bordeaux, CADIS, LAPSAC; F. Dubet, Lapeyronnie, Les quartiers d'exil, Paris, Ed. du Seuil, 1992. 
igualdade de todos. Nas sociedades democráticas, os indivíduos só podem aspirar à igualdade se são livres; se, como diz Rousseau, "todo homem nasce livre e dono de si mesmo". Esse domínio de si mesmo, essa capacidade de ser soberano, não é a garantia de igualdade real, mas a condição de igualdade de oportunidades e, pois, de desigualdades justas, por decorrerem de uma competição entre iguais. É neste sentido que a liberdade e a igualdade, que podem estar freqüentemente em oposição, podem estar também em harmonia. A igualdade engendra a obrigação de ser livre e de ser para si mesmo sua própria medida. Às falsas hierarquias só podemos opor as hierarquias justas, fundadas no mérito, na responsabilidade e na liberdade dos indivíduos.

Da Reforma ao Iluminismo, a concepção moderna do indivíduo sempre afirmou o vínculo de necessidade da igualdade e da liberdade, o que gera uma definição "heróica" do sujeito que se constrói a si mesmo, que se torna o autor de sua própria vida, de seus sucessos como de suas derrotas. O fato de tal ideal nunca ter sido plenamente realizado não impede, longe disso, que ele se imponha como a única norma da igualdade suscetível de produzir desigualdades, também elas aceitáveis. É, sem dúvida, porque o esporte é uma encenação dramática deste confronto entre a igualdade dos competidores e a hierarquia justa dos desempenhos, que ele aparece como o cenário principal no qual se confrontam os deuses da democracia (a igualdade) e os do capitalismo (o mérito e o trabalho). Mas a obrigação de ser livre como condição da igualdade coloca os indivíduos em uma série de situações subjetivas de prova que são as provas da igualdade ou, mais exatamente, as provas decorrentes do confronto entre o desejo de igualdade e as desigualdades reais. Quanto mais a liberdade e a autonomia do sujeito se impõem, mais essa prova expõe a pessoa e pode ser vivida como destruidora.

4.2 As provas da igualdade podem ser demonstradas em uma série de configurações específicas.

4.2.1 A consciência infeliz. Como a igualdade exige a auto-responsabilidade, ela priva, progressiva- mente, os indivíduos da consolação inerente às sociedades legitimamente não igualitárias e não democráticas. Os grandes sistemas de consolação, religiosos e políticos, que explicam e justificam as desigualdades, independentemente da ação dos indivíduos, já não conseguem explicar, de maneira eficaz, as desigualdades sociais e os fracassos dos indivíduos. O indivíduo se considera, então, responsável por sua própria infelicidade e se deixa invadir pela consciência infeliz. O triunfo do princípio de igualdade dissocializa a experiência das desigualdades numa sociedade que permanece fundamentalmente não igualitária, mas que tende a produzir desigualdades através de uma série de provas individuais e não mais de lutas coletivas ou, mais precisamente, que tende a diluir as lutas coletivas em provas pessoais.

Observemos o caso da experiência das desigualdades escolares ${ }^{36}$ durante muito tempo, o sistema escolar francês foi estruturalmente não igualitário, estando o acesso às diferentes carreiras diretamente determinado desde o berço: a cada categoria social um tipo de escola e, conseqüentemente, um tipo de chance de sucesso. Assim, as crianças do povo iam à escola do povo, as crianças da burguesia ao liceu e alguns indivíduos particularmente "dotados" e aplicados escapavam dessa canalização social das carreiras escolares. Como, desde o nascimento, os indivíduos não eram considerados iguais perante a educação, os insucessos escolares podiam ser facilmente explicados por causas sociais, pela injustiça do sistema e, às vezes, pelas injustiças "naturais", sendo as crianças do povo consideradas menos "dotadas" e menos "ambiciosas" que as da burguesia. A "vantagem" de tal sistema era a de não questionar a auto-estima dos alunos sem acesso às carreiras mais valorizadas que, aliás, não eram feitas para eles. Cada um podia explicar seus insucessos como conseqüência de causas sociais, de

${ }^{36}$ F. Dubet, D. Martuccelli, A l'école; sociologie de l'expérience scolaire. Paris, Ed. du Seuil, 1996; F. Dubet, Sentiments de justice dans l'expérience scolaire, em D. Meuret (ed), La justice du système éducatif, Bruxelles, De Boeck, 1999. 
causas exteriores a ele e a seu próprio valor. Um adolescente que se tornasse operário e uma jovem que se tornasse mãe e dona-de-casa, ao final da escolarização, podiam culpar as injustiças sociais quando tal destino lhes parecesse injusto, sem se verem, pessoalmente, como a causa de tal percurso de vida.

Tudo muda na escola democrática de massa que se empenha, e não só formalmente, em oferecer condições iguais de oportunidades. Os alunos já não são selecionados na entrada do sistema escolar, mas, sim, durante os estudos, em função unicamente de seu desempenho. É evidente que os sociólogos não ignoram que essa competição é socialmente determinada pelas desigualdades sociais, o que, contudo, não impede que, do ponto de vista dos indivíduos, seus sucessos e insucessos dependam essencialmente de seu desempenho e de sua qualidade. Não fracasso na escola porque sou filho de trabalhador sem acesso ao liceu e condenado a ganhar a vida precocemente, mas porque meu desempenho é fraco. Então, como conciliar a afirmação da igualdade de todos com a desigualdade do mérito de cada um, como tornar compatíveis as duas faces da igualdade?

Em um sistema republicano que afirma profundamente sua vocação democrática, como no caso francês, é o trabalho que serve de mediador entre esses dois princípios opostos. As desigualdades são justas e não colocam em dúvida a igualdade dos indivíduos se admitirmos que o desempenho dos alunos resulta do seu empenho voluntário durante a trajetória escolar. ${ }^{37}$ Enquanto os indivíduos pensam que suas desigualdades escolares decorrem do trabalho que realizam livremente, a igualdade fundamental está garantida. Quando descobrem, o que é comum, que não são iguais aos demais apesar do trabalho que realizam, só lhes resta duvidar de seu próprio valor, de sua própria igualdade. Eles só podem se auto-responsabilizar, se sentir inferiores, o que lhes deixa a opção entre a retirada de

${ }^{37}$ Dominique Méda insiste nesse papel do trabalho como princípio de justiça na economia política clássica, principalmente Adam Smith, em Le Travail, une valeur en voie de disparition, Paris, Aubier, 1995. um jogo em que estão perdendo e a violência, a destruição desse jogo. É porque as transformações dos mecanismos de formação das desigualdades individualizam as desigualdades, que as desigualdades levam à perda de auto-estima e à consciência infeliz. A "meritocracia" escolar pode ser um princípio libertador, o que não impede que legitime as desigualdades, na medida em que atribui sua responsabilidade às próprias vítimas. ${ }^{38}$

4.2.2 O desprezo. O apelo a uma concepção heróica do "sujeito igual" amplia a experiência do desprezo, já que a pessoa não conta mais com estruturas sociais e culturais não igualitárias que a impediriam de ser livre e responsável. Quando cada um é responsável por sua própria vida, se expõe ao desprezo que acompanha o fato de não ser digno dessa liberdade e de não poder assumir essa igualdade. ${ }^{39}$ Ao mesmo tempo que fizeram apelo à igualdade, os intelectuais da modernidade manifestaram um gosto aristocrático pronunciado pelas vanguardas e um desprezo igualmente pronunciado, pelas massas e preferências "pequenoburguesas". De fato, se cada um deve ser autônomo, importa primeiro que seja reconhecido como uma pessoa especial, original, capaz de construir sua vida sem se submeter a outros princípios que não os seus próprios. Enquanto a vergonha vem do sentimento de ser desmascarado, o desprezo vem do desejo de reconhecimento de si, do seu caráter único; a vergonha surge quando o indivíduo é destituído de seu papel, o desprezo, quando ele é reduzido a seu papel, quando não é reconhecido.

Como está, inevitavelmente, ligado ao princípio de auto-responsabilidade, o desejo de igualdade traz

${ }^{38}$ É claro que esse tipo de raciocínio não vale apenas no espaço escolar. Pode também dizer respeito a todas as experiências que colocam frente a frente a igualdade dos sujeitos e suas desigualdades de desempenho: o esporte, o trabalho, mas também o amor que é uma forma de competição na qual cada um deve confirmar seu próprio valor.

${ }^{39}$ A. Honneth, La lutte pour la reconnaissance, Paris, Cerf, 2000 . 
consigo uma exigência contínua de reconhecimento. Assim, a prova da dominação e das desigualdades injustas é primeiramente vivida como uma manifestação de desprezo, de redução da pessoa ao seu papel e ao olhar do outro. Os que afirmam que o triunfo do individualismo democrático esvazia o trabalho de todo estado de conflito enfraquecendo as comunidades se enganam profundamente. Para além das reivindicações de salário, existem sempre lutas contra o desprezo, contra a ignorância do valor específico dos indivíduos. Este é, freqüentemente, o ponto central dos protestos e articulações que escapam aos jogos sindicais tradicionais. Os pobres não aceitam ser reduzidos ao status de casos sociais, ser ignorados e, sobretudo, ser obrigados a se afirmarem como sujeitos portadores de projetos, no momento mesmo em que tal capacidade lhes é tirada. Os alunos de liceu vêem as hierarquias escolares como cadeias de desprezo nas quais cada um despreza o outro para se sentir menos desprezível. Basta observarmos a obsessão do semblante e do desafio que comanda a sociabilidade dos jovens da periferia, para vermos até que ponto o desprezo é tido como o sentimento social elementar daqueles que esbarram na contradição aguda entre igualdade fundamental e desigualdades sociais. ${ }^{40}$ Mas, enquanto a vergonha socializa a experiência social, o desprezo a dissocializa, transforma-a em um caso de pura auto-imagem, degradando a experiência de classe em uma série de interações narcísicas ou de afrontamento, como nas análises de Goffman, cuja sociologia é mais interessante quando concebida como uma antropologia da modernidade que como expressão de um paradigma sociológico.

4.2.3 Retirada e violência. Nas situações dominadas pela consciência infeliz e pelo desprezo, sobretudo nos jovens, quando os valores individuais são colocados à prova, várias estratégias são delineadas conforme o modelo de Hirschman. ${ }^{41}$ Muitos atores preservam sua auto-estima, recusando-se a participar de

${ }^{40}$ F. Dubet, La galère, Paris, Fayard, 1987.

${ }^{41}$ A. Hirschman, Exit, Voice and Loyalty, Cambridge, Cambridge University Press, 1970. um jogo no qual acham que vão perder sempre. Assim, alguns alunos decidem que não vão se esforçar para que seu desempenho não coloque em questão seu valor, sua igualdade fundamental; eles "decidiram" fracassar na escola, o que lhes evita serem afetados por seus insucessos. Enquanto um mau resultado numa tarefa é insuportável, ele se torna insignificante, quando o indivíduo decidiu não cumprir com seu dever. Mais que tal forma radical de retirada, observamos na escola e também nos bairros desfavorecidos todo um conjunto de estratégias que consiste em fazer de conta. Os alunos negociam um conformismo escolar limitado em troca de notas médias que lhes assegurem uma sobrevivência tranqüila no sistema. Ameaçando os professores de se retirarem completamente do jogo ou de serem violentos, acabam obtendo um equilíbrio precário no qual uma boa vontade explícita lhes garante notas médias. Da mesma maneira, os usuários dos serviços sociais negociam certa boa vontade em troca de uma assistência indexada ao seu desejo de se "virarem". Nesse caso, como na escola, ninguém se engana num jogo cuja forma se mantém, mas cujo conteúdo se esvazia, enquanto as aparências são mantidas.

Outros alunos rompem o jogo pela violência que aparece como o único meio de recusar a imagem negativa de si, provocada por seu insucesso e sua liberdade. Os alunos invalidam o jogo escolar, agredindo os professores e transformando-os em inimigos. A violência possibilita salvar sua dignidade e também engrandecer seu autor perante o grupo de iguais. Podemos, no entanto, nos perguntar por que tal violência não se transforma em conflito, por que não coloca em questão os mecanismos estruturais das desigualdades escolares. Justamente, o recurso à violência se explica por tal impossibilidade e pelo fato de as provas da igualdade serem provas individuais numa sociedade ao mesmo tempo democrática e competitiva. No fundo, os alunos violentos rompem esse jogo porque acreditam nele tanto quanto os outros, se não mais. Na violência, eles invertem o jogo que os destroe, mas não propõem nenhum outro, como o mostra a cultura do desafio que organiza a vida e o modo de consumo deles. 
4.3 Se admitimos os fundamentos de tal raciocínio, temos também de admitir sua consequiência principal, ou seja, a tensão entre os dois lados da igualdade e o crescimento dessa tensão à medida que a igualdade democrática se desenvolve e que o mercado e o mérito estendem seu reinado. Do ponto de vista dos indivíduos e de suas experiências, tal contradição só pode ser superada pelo apelo ao respeito e ao reconhecimento. $\mathrm{O}$ respeito se impõe desde que as desigualdades de mérito e de desempenho não devam afetar a igualdade entre as pessoas. Desse ponto de vista, o desprezo aparece como confusão entre as esferas de justiça, quando as desigualdades de desempenho desqualificam os indivíduos enquanto sujeitos livres e iguais. Por exemplo, os alunos admitem as classificações e as hierarquias escolares, desde que os piores alunos não sejam desprezados nem maltratados e que o julgamento da pessoa e o do desempenho sejam claramente diferenciados. Isso é também o que esperam os usuários dos serviços sociais, quando afirmam que nem a pobreza nem o desemprego devem tirar o valor da pessoa, nem afetar as condições de igualdade.

O tema do respeito introduz uma mudança essencial na natureza dos princípios de justiça. A igualdade de todos é uma norma universal, uma ficção, um postulado que não tem necessidade de ser fundamentado empiricamente: as raças são iguais, os sexos são iguais, os seres humanos são iguais por princípio. As desigualdades funcionais do mérito são também de natureza objetiva e universal; elas são a sanção dos mecanismos impessoais do mercado de trabalho e dos concursos. ${ }^{42}$ E mesmo sabendo que essas provas são sempre "um jogo de cartas marcadas", sabemos também que permanecem objetivas e justas em seu princípio, como o implica o tema da igualdade de oportunidades. Ao contrário, o tema do respeito é necessariamente indexado às particularidades individuais, naturais ou reivindica-

${ }^{42}$ Geralmente, aqueles que não gostam do mercado de trabalho gostam dos concursos, e vice-versa; mas este desacordo quanto aos procedimentos não os opõe com relação à crença nas desigualdades injustas. das, exigindo o reconhecimento de características e de experiências específicas. Peço que me respeitem enquanto mulher, minoria cultural, comunidade de convicção; peço que me reconheçam como tal para que eu não seja destruída pelo choque entre as duas formas da igualdade. É por tal razão que o confronto entre o princípio de igualdade e as desigualdades "funcionais" faz surgir uma reivindicação de reconhecimento como espaço das identidades e da civilidade. É por tal razão que os movimentos sociais igualitários estão também centrados no reconhecimento de particularismos. Nesse contexto, a reivindicação de igualdade nunca está separada de uma reivindicação de reconhecimento e de especificidade. ${ }^{43}$ Se o princípio de igualdade consiste em ser dono de sua própria vida, o princípio de reconhecimento faz com que esse domínio se subtraia parcialmente às provas do mercado e do mérito.

A globalização provoca certamente o retorno das identidades, das culturas e das nações. Mas não podemos explicar tal retorno, como o faz Huntington, pelo caráter irredutível das diferenças ou pela defesa do local e do específico contra o universal do mercado, confundido, no caso, com o modelo norte-americano. ${ }^{44}$ De modo mais fundamental, o tema do reconhecimento das identidades surge necessariamente como o único modo de "síntese" e de conciliação possível das duas faces da igualdade ou da igualdade dos indivíduos com as desigualdades coletivas. Aliás, a maioria dos movimentos sociais "clássicos", de alguns anos para cá, assumiram dimensão identitária e nacional.

O rompimento dos registros e das dimensões da igualdade se traduz por multiplicação das escalas de hierarquização das desigualdades e por dissociação relativa da dominação e dos critérios de estratificação. Isso não significa que haja crescimento ou dimi-

${ }^{43}$ É uma lógica que o universalismo republicano tem dificuldade de aceitar, convencido de que só o funcionamento das instituições meritocráticas pode garantir a contabilidade da igualdade de todos e das desigualdades justas. H. Mendras, op. cit.

${ }^{44}$ S. Huntington, "The clash of civilization", Foreign Affairs, v. $72, \mathrm{n}^{\circ} 3,1993$. 
nuição das desigualdades, pois se elas aumentam segundo alguns indicadores, se reduzem segundo outros. E nada nos impede de nos indignarmos diante do caráter escandaloso de muitas desigualdades. Contudo, do ponto de vista sociológico, aquela observação significa que as desigualdades já não formam um sistema, supondo que um dia tenha sido o caso, mas que formam um conjunto de tensões e de problemas em cada momento específicos. É inevitável constatar que o marxismo não foi substituído por uma concepção estrutural homogênea e satisfatória das desigualdades que explique, ao mesmo tempo, as condutas dos atores e o funcionamento de uma estrutura. Tal situação não deve, no entanto, nos conduzir nem à negação das desigualdades nem a sua simples denúncia que proporciona mais benefícios morais que satisfações intelectuais. Devemos, na melhor das hipóteses, nos satisfazer com teorias ad hoc em função dos problemas estudados.

Encontraremos questões e problemáticas globais mais satisfatórias no âmbito da filosofia política, que se incumbe diretamente da diversidade dos critérios de justiça que comandam toda análise das desigualdades. Quais são as desigualdades justas, pergunta Rawls. Como manter a separação das esferas de justiça, per- gunta Walzer. Como conciliar o reconhecimento e os valores universais, interroga Taylor. Evidentemente, nenhuma dessas perguntas é diretamente sociológica. Mas seria tão difícil transformá-las em programas de pesquisa sociológica, empírica e teórica? Fazendo tal esforço, a sociologia não perderia sua alma, talvez mesmo a reencontrasse. Esse é o caminho se quisermos que ela não se reduza nem a um recenseamento nem à descrição cada vez mais refinada de práticas, elas próprias cada vez mais refinadas e, às vezes, cada vez mais insignificantes. Os pais "fundadores" fizeram da sociologia outra maneira de fazer política e filosofia social e é por essa razão que ela nos interessa tanto hoje.

FRANÇOIS DUBET é professor da Universidade de Bordeaux II, pesquisador do CNRS (École des Hautes Etudes en Sciences Sociales/CADIZ). Autor de, entre outros: Sociologia da Experiência, Lisboa, Instituto Piaget, 1994; De la Galère: jeunes en survie Paris, Fayard, 1987; A l'école: sociologie de l'expérience scolaire, em colaboração com Danilo Martuccelli, Paris, Ed. du Seuil, 1996 e A formação dos indivíduos: a desinstitucionalização, Contemporaneidade e Educação, ano 3, n 3, p. 27-33, março 1998. 


\section{Resumos/Abstracts}

François Dubet

\section{As desigualdades multiplicadas}

Nossas sociedades são dominadas por uma contradição fundamental: como sociedades democráticas, afirmam a igualdade por essência de todos os sujeitos. Como sociedades capitalistas, não param de construir mercados que hierarquizam as competências e os méritos. Tal contradição parece cada vez menos superada. Como conciliar a igualdade de todos e o mérito de cada um? Presenciamos o surgimento de movimentos sociais que reivindicam o reconhecimento dos indivíduos - independentemente do seu mérito - e uma igualdade de princípio que se converte facilmente em culpa, em desprezo e em violência. De fato, sem renunciar à busca da igualdade, a dupla natureza de nossas sociedades exige que constituamos uma política de reconhecimento do sujeito.

\section{Multiplying the inequalities}

Our societies are dominated by a fundamental contradiction: as democratic societies, they affirm the essential equality of all subjects but as capitalist societies they do not cease to construct markets which establish hierarchies of competence and merit. This contradiction appears to increase rather than diminish. How is it possible to reconcile equality for all and individual merit? Social movements are created which demand the recognition of individuals - independent of merit - and a principle of equality that is easily converted into blame, contempt and violence. Without abandoning the search for equality, the double nature of our societies requires that we establish a policy for the recognition of the subject.

\section{Les inégalités multipliées}

Nos sociétés sont dominées par une contradiction fondamentale: sociétés démocratiques, elles affirment l'égalité par essence de tous les sujets; sociétés capitalistes, elles ne cessent de construire des marchés Qui hérarchisent les compétences et les mérites. Cette contradiction semble de moins en moins maïtrisée. Comment concilier l'égalité de tous et le mérite de chacun? On voit se former des mouvements sociaux qui en appellent à la reconnnaissance des individus - indépendament de leur mérite - et à une égalité de principe qui se retourne aisément en culpabilité, en mépris et en violence. En fait, tout en ne renonçant pas à la recherche de l'égalité, la double nature de nos sociétés exige que se forme une politique de reconnaissance du sujet.
Marlene Ribeiro

Trabalho cooperativo no MST e ensino fundamental rural: desafios à educação básica

O objetivo deste artigo é averiguar que desafios o trabalho cooperativo, desenvolvido por agricultores assentados, coloca à escola básica. A metodologia articula uma revisão bibliográfica sobre economia solidária com a pesquisa-ação, feita em assentamentos de reforma agrária e escolas rurais, no município de Piratini/RS, focalizando a relação entre o trabalho cooperativo e a educação escolar. As falas dos sujeitos evidenciam o conflito entre a formação exigida pelo trabalho cooperativo agrícola e o modelo de escola básica em que se fundamenta a educação rural.

Co-operative work: challenges for the primary school

The purpose of this paper is to identify those challenges which cooperative work, developed by 'settled' farmers, raise for the primary school. The methodology involves a literature review about economic solidarity and actionresearch carried out in settlements established by the Land Reform and in rural schools in the municipality of Piratini/RS. The research focuses on the relation between co-operative 